ARTICLE

Received 25 Sep 2015 | Accepted 15 Jan 2016 | Published 18 Feb 2016

DOI: $10.1038 /$ ncomms10748

OPEN

\title{
Three-dimensional porous hollow fibre copper electrodes for efficient and high-rate electrochemical carbon dioxide reduction
}

\author{
Recep Kas' ${ }^{1}$ Khalid Khazzal Hummadi1,2, Ruud Kortlever ${ }^{3}$, Patrick de Wit ${ }^{4}$, Alexander Milbrat ${ }^{1,5}$, \\ Mieke W.J. Luiten-Olieman ${ }^{4}$, Nieck E. Benes ${ }^{4}$, Marc T.M. Koper ${ }^{3}$ \& Guido Mul ${ }^{1}$
}

Aqueous-phase electrochemical reduction of carbon dioxide requires an active, earthabundant electrocatalyst, as well as highly efficient mass transport. Here we report the design of a porous hollow fibre copper electrode with a compact three-dimensional geometry, which provides a large area, three-phase boundary for gas-liquid reactions. The performance of the copper electrode is significantly enhanced; at overpotentials between 200 and $400 \mathrm{mV}$, faradaic efficiencies for carbon dioxide reduction up to $85 \%$ are obtained. Moreover, the carbon monoxide formation rate is at least one order of magnitude larger when compared with state-of-the-art nanocrystalline copper electrodes. Copper hollow fibre electrodes can be prepared via a facile method that is compatible with existing large-scale production processes. The results of this study may inspire the development of new types of microtubular electrodes for electrochemical processes in which at least one gas-phase reactant is involved, such as in fuel cell technology.

\footnotetext{
${ }^{1}$ PhotoCatalytic Synthesis Group, Faculty of Science and Technology, MESA+ Institute for Nanotechnology, University of Twente, Meander 229, P.O. Box 217, 7500 AE Enschede, The Netherlands. ${ }^{2}$ College of Engineering, University of Baghdad, P.O. Box 47024, 10071 Aljadria, Baghdad, Iraq. ${ }^{3}$ Leiden Institute of Chemistry, Leiden University, Einsteinweg 55, P.O. Box 9502, 2300 RA Leiden, The Netherlands. ${ }^{4}$ Inorganic Membranes Group, Faculty of Science and Technology, MESA + Institute for Nanotechnology, University of Twente, P.O. Box 217, 7500 AE Enschede, The Netherlands. ${ }^{5}$ Molecular Nanofabrication Group, Faculty of Science and Technology, MESA+ Institute for Nanotechnology, University of Twente, P.O. Box 217, 7500 AE Enschede, The Netherlands. Correspondence and requests for materials should be addressed to K.K.H. (email: A.khalidkhazzalhummadi@utwente.nl) or to G.M. (email: G.mul@utwente.nl).
} 
T he accumulation of carbon dioxide $\left(\mathrm{CO}_{2}\right)$ in the atmosphere is generally accepted to have a significant impact on (local) climate conditions ${ }^{1-3}$. Immediate measures must be taken to minimize carbon emissions and to mitigate this impact ${ }^{4}$. A promising methodology contributing to reduction of $\mathrm{CO}_{2}$ emissions is to electrochemically convert $\mathrm{CO}_{2}$ to useful chemicals, while using electricity generated by renewable energy sources ${ }^{5-7}$. Then, an efficient, preferably cheap, and stable electrocatalyst, which can reduce $\mathrm{CO}_{2}$ at high current densities, is required ${ }^{8}$. In recent years, significant progress in understanding and enhancing performance of electrodes in electrochemical $\mathrm{CO}_{2}$ reduction has been made. For example, formation of carbon monoxide $(\mathrm{CO})$ at low potentials using noble metals in aqueous electrolytes has been reported with high selectivity over hydrogen formation, albeit at low current densities ${ }^{9-11}$. Higher current densities, maintaining $\mathrm{CO}$ production selectivity, were obtained by using ionic liquids as electrolyte ${ }^{12,13}$. However, practical application of ionic liquids is challenging, as cost is generally high and stability questionable ${ }^{9,14}$. An attractive alternative for noble metal electrodes is the use of copper electrodes. Copper electrodes are well known to produce hydrocarbons from $\mathrm{CO}_{2}$, with the onset potential $(\approx 0.5$ to $-0.7 \mathrm{~V}$ versus reversible hydrogen electrode (RHE)) depending on the preparation method ${ }^{15-17}$. In general, potentials of -0.8 to $-1 \mathrm{~V}$ versus RHE are necessary to obtain reasonable faradaic efficiency (FE) for products of $\mathrm{CO}_{2}$ reduction on these electrodes. Although less expensive and much more abundant than other $\mathrm{CO}$ evolving electrodes, poor activity, selectivity and stability in the formation of $\mathrm{CO}$ and formic acid prevent the practical application of polycrystalline copper ${ }^{18,19}$. Recently, Li et al..$^{20}$ reported production of $\mathrm{CO}$ and formic acid with reasonable $\mathrm{FE}$ at low overpotentials on copper nanoparticles, when synthesized by electrochemical reduction of copper oxides. At a potential of $-0.5 \mathrm{~V}$ versus RHE, a partial current density of $2.1 \mathrm{~mA} \mathrm{~cm}^{-2}$ for $\mathrm{CO}_{2}$ reduction was obtained, yielding an $\mathrm{FE}$ of $35 \%$ for $\mathrm{CO}$ and $33 \%$ for formic acid. Ethylene and methane are other products typically observed in aqueous-phase $\mathrm{CO}_{2}$ reduction, which are extensively formed at more negative potentials than $-0.5 \mathrm{~V}$ versus $\mathrm{RHE}^{21}$.

Besides the structural requirements of the copper electrodes, process conditions need to be optimized as well, to allow efficient electrochemical reduction. Inorganic hollow fibres and microtubular electrodes have been applied as component in solid oxide fuel cells. A high power output and low fabrication costs are beneficial properties of such electrode configurations ${ }^{22-24}$. In aqueous electrolytes, hollow fibres composed of nickel and carbon have also been used as cathode for proton or oxygen reduction, respectively ${ }^{25,26}$. Finally, microtubular gas diffusion electrodes (GDEs) made of carbon nanotubes have been applied in aqueous-phase electrochemical conversions ${ }^{27}$. Here we demonstrate that $\mathrm{Cu}$ hollow fibre electrodes are very efficient in electrocatalytic conversion of $\mathrm{CO}_{2}$, owing to their porous structure and excellent mass transport properties. Not only the hydrogen evolution reaction is suppressed on these electrodes to levels not reached previously on copper surfaces to the best of our knowledge, but also the overall current density for $\mathrm{CO}_{2}$ reduction is unprecedentedly high at low potentials.

\section{Results}

Physical characterization of the copper hollow fibres. The preparation of metal hollow fibres from nickel and stainless steel has been described in the literature previously ${ }^{28,29}$. We adapted this method and prepared $\mathrm{Cu}$ hollow fibres using a mixture containing copper particles, polymer and solvent. This mixture was pressed through a spinneret into a coagulation bath. In this bath, non-solvent induced phase separation arrests the copper particles in the polymer matrix. Owing to the use of a bore liquid during spinning, hollow fibres were obtained. By thermal treatment, the polymer was decomposed and the copper particles sintered together, resulting in hollow, porous $\mathrm{CuO}$ fibres ${ }^{30}$. Hydrogenation of these $\mathrm{CuO}$ fibres at elevated temperatures was applied to convert $\mathrm{CuO}$ into metallic copper. The details of the physical characterization and X-ray diffraction patterns of the copper powder and the fibres can be found in Supplementary Fig. 1. A typical scanning electron microscope (SEM) image of the precursor $\mathrm{Cu}$ powder is shown in Supplementary Fig. 2 and of the hollow fibres in Fig. 1 (see Supplementary Fig. 3 for the locations at which these images were taken). The images of the external surface of the fibres show that the fibre is composed of aggregated copper particles forming an interconnected three-dimensional (3D) porous structure (Fig. 1a,b). The cross-sectional images of the deliberately broken fibres exhibit finger-like voids perpendicular to the surface that are terminated by a $10-$ to $15-\mu \mathrm{m}$-thick sponge-like porous outer layer (Fig. 1c,d). Cu hollow fibres have outer and inner diameters ranging from $1.55 \pm 0.1$ to $1.3 \pm 0.05 \mathrm{~mm}$, respectively (Fig. 1e). $\mathrm{CO}_{2}$ was purged from the inside out of the fibre, needing an overpressure of $1.70 \pm 0.1 \mathrm{bar}$ due to the resistance of the porous structure. Gas bubbles emerging out of the fibre can be clearly seen in Fig. If (see also Supplementary Movie 1). The pressure is considered to drop evenly across the outer porous layer to 1.05 bar.

Electrocatalytic performance of the copper hollow fibres. Linear sweep voltammetry was performed in $\mathrm{Ar}$ or $\mathrm{CO}_{2}$ saturated electrolyte, while $\mathrm{Ar}$ or $\mathrm{CO}_{2}$ were purged through the fibres (Fig. 2a). The current densities recorded during Ar purge are due to evolution of hydrogen, which has an onset potential of around $-0.25 \mathrm{~V}$ versus RHE. Purging of $\mathrm{CO}_{2}$ through the fibre wall leads to a $c a$. twofold increase in cathodic current density at potentials between -0.2 and $-0.4 \mathrm{~V}$ versus RHE. This is contrary to the literature, in which for smooth or rough copper surfaces lower current densities were reported in $\mathrm{CO}_{2}$ atmosphere as compared with $\mathrm{Ar}$ atmosphere ${ }^{31,32}$. Extensive coverage of the $\mathrm{Cu}$ surface by $\mathrm{CO}$, inhibiting the hydrogen evolution reaction, was proposed to explain the lower current density recorded during $\mathrm{CO}_{2}$ electroreduction on polycrystalline copper electrodes ${ }^{33}$. Thus, the high cathodic current achieved in the presence of $\mathrm{CO}_{2}$ in this study is already an indication of distinctive performance of $\mathrm{Cu}$ hollow fibres towards $\mathrm{CO}_{2}$ reduction.

The FE of the major products was measured by varying the applied potential between -0.15 and $-0.55 \mathrm{~V}$ versus RHE (Fig. 2b). The onset of $\mathrm{CO}$ formation can be observed at $-0.15 \mathrm{~V}$ versus RHE, implying an overpotential of just $\approx 40 \mathrm{mV}$ above the equilibrium potential $(-0.11 \mathrm{~V}$ versus $\mathrm{RHE})$. The total $\mathrm{FE}$ efficiency of $\mathrm{CO}_{2}$ reduction products adds up to $\approx 85 \%$ at potentials between -0.3 and $-0.5 \mathrm{~V}$ versus RHE. Specifically, a maximum $\mathrm{FE}$ of $\approx 72 \%$ was obtained towards $\mathrm{CO}$ at a potential of $-0.4 \mathrm{~V}$ versus RHE, whereas in the literature a maximum FE for $\mathrm{CO}$ on polycrystalline copper and copper nanoparticles has been reported of only $20 \%$ ( $-0.8 \mathrm{~V}$ versus RHE) or $45 \%$ $\left(J_{\mathrm{CO}} \approx 300 \mu \mathrm{Acm}^{-2}\right)$, respectively ${ }^{19,20}$. The decrease in $\mathrm{FE}$ of $\mathrm{CO}$ at more negative potentials $(<-0.5 \mathrm{~V}$; Fig. $2 \mathrm{~b})$ implies $\mathrm{CO}$ formation is most probably limited by desorption or consecutive surface reactions at these more negative potentials. Indeed, ethylene was detected (Supplementary Table 1) at these conditions, which is probably formed by coupling of two $\mathrm{CO}$ molecules ${ }^{34}$.

The electrokinetic data, represented by the Tafel plot, are shown in Fig. 2c. The first step in the process of $\mathrm{CO}_{2}$ activation involves electron transfer to adsorbed $\mathrm{CO}_{2}$, which is probably 

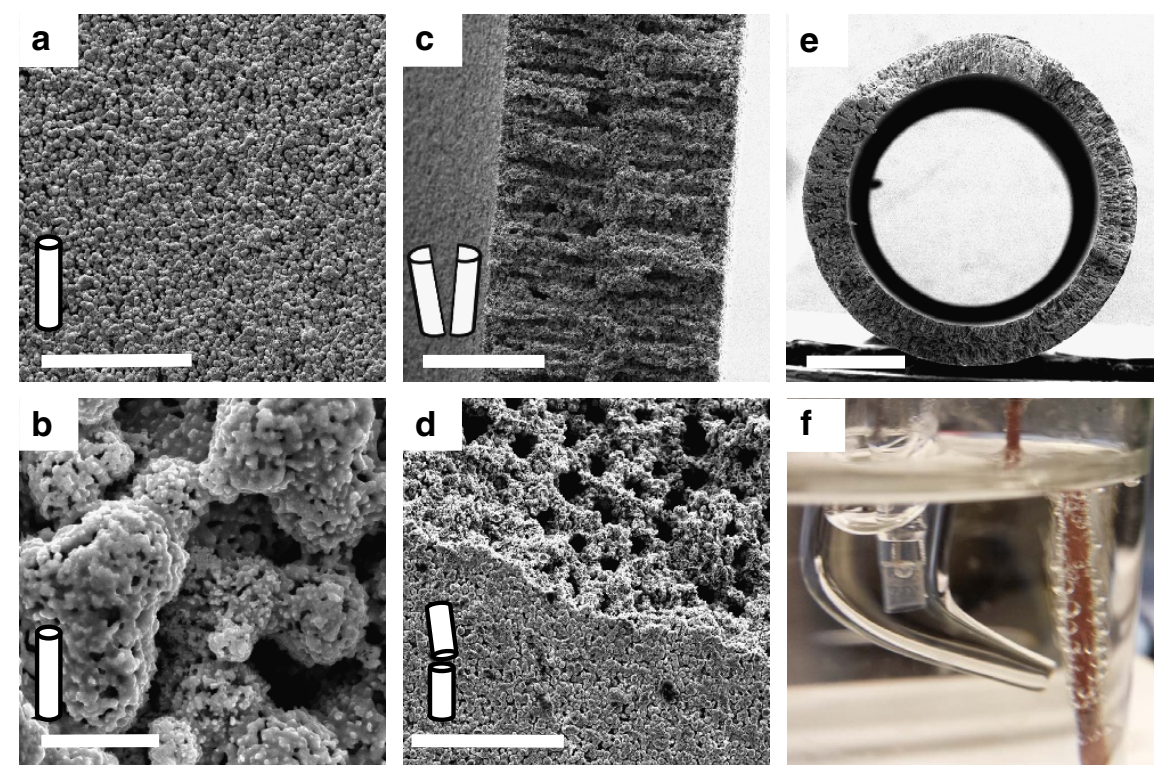

Figure 1 | Physical characterization of Cu hollow fibres. (a) SEM images of low and (b) high magnification of the outer surface of the Cu hollow fibre. Scale bars, 50 and $2 \mu \mathrm{m}$, respectively. (c) Cross-sectional image of a perpendicularly broken Cu hollow fibre. Scale bar, $100 \mu \mathrm{m}$. (d) Outer surface and cross-section of a Cu hollow fibre in the parallel direction to the length of the hollow fibre. Scale bar, $50 \mu \mathrm{m}$. (e) Cross-sectional image of the Cu hollow fibre taken at low magnification. Scale bar, $500 \mu \mathrm{m}$. (f) Cu hollow fibre employed as an electrode at $20 \mathrm{ml} \mathrm{min}^{-1}$ gas flow.

a

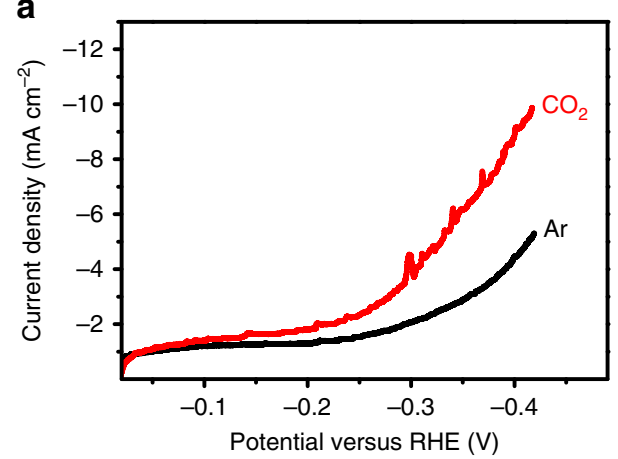

C

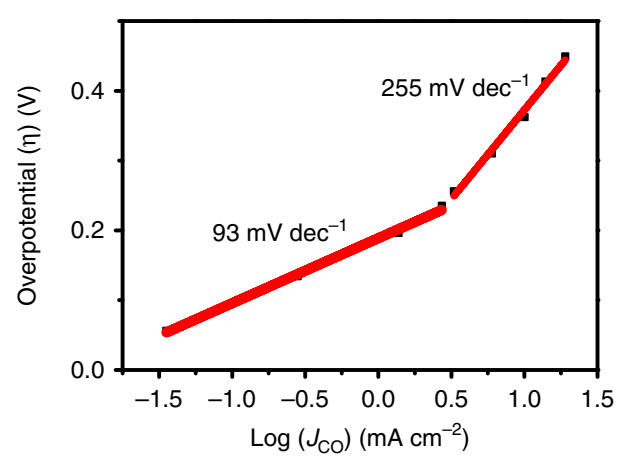

b

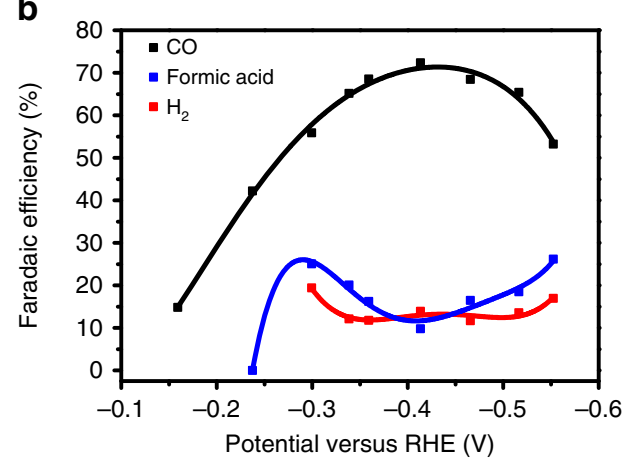

d

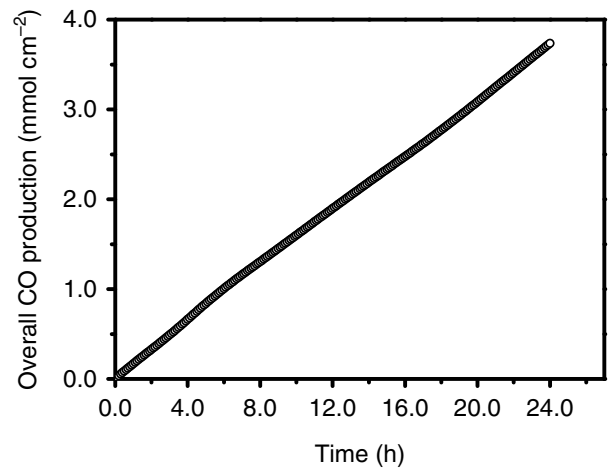

Figure 2 | Electrocatalytic performance of the Cu hollow fibres. (a) Linear polarization curves obtained for $\mathrm{Cu}$ hollow fibres when $\mathrm{CO}_{2}$ or $\mathrm{Ar}_{\mathrm{r}}$ was purged in $0.3 \mathrm{M} \mathrm{KHCO}_{3}$ electrolyte (scan rate: $50 \mathrm{mVs}^{-1}$ ). (b) $\mathrm{FE}$ of $\mathrm{CO}$, formic acid and $\mathrm{H}_{2}$ as a function of applied potential, using a $\mathrm{CO}_{2}$ purge of $20 \mathrm{ml}$ min ${ }^{-1}$. (c) Overpotential versus partial current density of $\mathrm{CO}$ using $\mathrm{Cu}$ hollow fibres (flow rate of $\mathrm{CO}_{2}: 20 \mathrm{ml} \mathrm{min}^{-1}$ ). (d) Total production of $\mathrm{CO}$ at an applied potential of $-0.4 \mathrm{~V}$ for $24 \mathrm{~h}$ of continuous experiment (flow rate of $\mathrm{CO}_{2}: 20 \mathrm{ml} \mathrm{min}^{-1}$ ).

proton assisted ${ }^{35}$. Subsequently, the $\mathrm{COOH}$ intermediate reacts with a second electron and proton to form $\mathrm{CO}$ and water. A Tafel slope of around $116 \mathrm{mV} \mathrm{dec}^{-1}$ has been assigned to a mechanism in which formation of this $\mathrm{COOH}$ intermediate is rate determining in the formation of $\mathrm{CO}$ (refs 17,20). The lower slope of $93 \mathrm{mV} \mathrm{dec}^{-1}$ observed in Fig. $2 \mathrm{c}$ is most probably due to a non-uniform potential or current distribution in the porous matrix of the hollow fibre. This might be caused by the extensive bubble formation and associated inhomogeneous distribution of reactants over the electrode surface. An apparent increase in Tafel 
slope can be observed in Fig. $2 c$ at more negative potentials, which suggests a change in rate-determining step. At these potentials, hollow fibres show lower selectivity towards formic acid than typically reported in the literature for smooth or rough copper surfaces 19,20 , whereas similar to copper nanoparticles at high pressures ${ }^{36}$, a very high selectivity towards CO is still obtained. The increase in CO selectivity at higher potentials might be associated with the participation of another $\mathrm{CO}_{2}$ molecule in the rate-determining step of the mechanism ${ }^{37}$.

To test the stability of the $\mathrm{Cu}$ hollow fibres, $24 \mathrm{~h}$ of continuous electrolysis was performed at an applied potential of $-0.4 \mathrm{~V}$ versus RHE (Fig. $2 \mathrm{~d}$ and Supplementary Fig. 4). After a $\approx 10 \%$ drop in activity in the first $7 \mathrm{~h}$, noticeable from the slight curvature of the plot in Fig. 2d, stable performance was achieved in the subsequent $17 \mathrm{~h}$ of experiment. SEM images of the morphology of the $\mathrm{Cu}$ hollow fibres before or after extensive electrolysis (Supplementary Fig. 5) did not show any differences. The activity of polycrystalline $\mathrm{Cu}$ typically diminishes very quickly (within an hour), unless very high purity electrolytes and electrodes $(99.9999 \%)$ are employed ${ }^{38}$. It is important to note that studies using $\mathrm{Cu}$ plates usually discuss ultra-high purity copper, whereas the purity of the precursor copper powders used in this study is relatively low (99\%), significantly reducing the price for commercial application. The observed stability of the hollow fibres is in agreement with that of $\mathrm{Cu}$ nanoparticles derived from $\mathrm{Cu}$-oxide precursor films ${ }^{20}$.

Figure $3 \mathrm{a}, \mathrm{b}$ show the effect of the $\mathrm{CO}_{2}$ flow rate on overall current density and FE of CO, respectively. The current density clearly depends on the $\mathrm{CO}_{2}$ flow rate up to $30 \mathrm{ml} \mathrm{min}^{-1}$, which yields a maximum $\mathrm{FE}$ of $75 \%$ at $-0.4 \mathrm{~V}$ versus RHE for CO. This FE is almost twice of what has been recently reported for copper nanoparticles at the same potential ${ }^{20}$. The change in FE towards $\mathrm{CO}$ as a function of $\mathrm{CO}_{2}$ flow rate is consistent with a concurrent increase in current density. These experiments indicate that the FE of $\mathrm{CO}$ strongly depends on the efficiency of mass transfer of $\mathrm{CO}_{2}$ to the electrode surface. Similarly, reasonable activity and $\mathrm{FE}$ towards formic acid and $\mathrm{CO}$ (FE of $45 \%$ at $-0.5 \mathrm{~V}$ versus RHE) were achieved using copper nanofoams prepared by electrodeposition ${ }^{39}$. The porous structure and thickness-dependent activity of nanofoams suggest that mass transfer phenomena inside the pores might play a role in improved selectivity towards $\mathrm{CO}_{2}$ electroreduction over hydrogen evolution. The steady behaviour above the flow rate of $30 \mathrm{mlmin}^{-1}$ implies most active sites are involved in converting $\mathrm{CO}_{2}$ to $\mathrm{CO}$ and the catalyst has reached its intrinsic limit. Previously, the $\mathrm{CO}_{2}$ reduction rate in aqueous conditions was shown to be proportional to the $\mathrm{CO}_{2}$ pressure applied, but optimized rates were not achieved even at pressures as high as
$25 \mathrm{~atm}$ (ref. 40). As previously stated, this might be explained by a slow desorption rate of $\mathrm{CO}$, a high $\mathrm{CO}$ surface coverage being supported by spectroscopic studies ${ }^{17}$. Therefore, the hollow fibre configuration might also be beneficial for $\left(\mathrm{CO}_{2}\right.$ stimulated) removal of $\mathrm{CO}$ from the surface, induced by the very high local concentration of $\mathrm{CO}_{2}$ near the electrode surface.

A comparison of the performance of our $\mathrm{Cu}$ hollow fibre to the performance of various electrodes, including those composed of other metals, is shown in Fig. 4. To this end, the partial current density of $\mathrm{CO}\left(J_{\mathrm{CO}}\right)$ is plotted against the applied potential. Figure 4 implies that $\mathrm{Cu}$ hollow fibres can reduce $\mathrm{CO}_{2}$ to $\mathrm{CO}$ electrochemically at a potential of $-0.4 \mathrm{~V}$ versus RHE with over 15 to 400 times higher rate than polycrystalline $\mathrm{Cu}$ and $\mathrm{Cu}$ nanoparticles, respectively (see for reproducibility the Supplementary Fig. 6) ${ }^{20}$. Although outcompeting these currently best-performing copper-based electrodes, $\mathrm{Cu}$ hollow fibres also show comparable performance at low potentials $(-0.2$ to $-0.6 \mathrm{~V}$ versus RHE) to that of noble metal catalysts evaluated in aqueous solutions ( $\mathrm{Au}$ nanoparticles ${ }^{11}$ or nanoporous $\mathrm{Ag}^{9}$ ). Although noble metal electrodes benefit from a high overpotential for hydrogen evolution, $\mathrm{Cu}$ hollow fibres perform so well on the basis of the extraordinary efficient mass transfer of $\mathrm{CO}_{2}$.

\section{Discussion}

Besides the aforementioned favourable mass transfer properties of the $\mathrm{Cu}$ hollow fibres, the remarkable formation of CO at very low overpotentials might also be associated with the nature of the copper sites obtained by hydrogen-induced reduction of $\mathrm{CuO}$ (refs 20,41). The efficiency of rough and porous copper electrodes has been attributed to the oxide-derived formation of metastable copper sites existing in grain boundaries ${ }^{42}$. Furthermore, Reske et al. $^{43}$ showed the reduction of $\mathrm{CO}_{2}$ to $\mathrm{CO}$ can be significantly enhanced by decreasing the size of the copper nanoparticles, which was correlated to the number of uncoordinated sites. The enhanced $\mathrm{CO}_{2}$ reduction observed at lower potentials on rough copper surfaces implies defect sites may be responsible for the increase in activity, which probably favour the formation of the $\mathrm{COOH}$ intermediate.

Analysis of the precursor copper powder and $\mathrm{Cu}$ hollow fibres, before and after electrolysis by X-ray photoelectron spectroscopy (XPS), indicate that major metal impurities at the surface are absent (Supplementary Fig. 7 and Supplementary Table 2). The major impurity is carbon, which is present in varying quantities in the copper powder used as precursor for synthesis, and hollow fibres before and after electrolysis. XPS spectra of the fibres further indicate that the surface, besides $\mathrm{Cu}^{0}$, contains some $\mathrm{Cu}_{2} \mathrm{O}$, the latter likely to be associated with the exposure of the
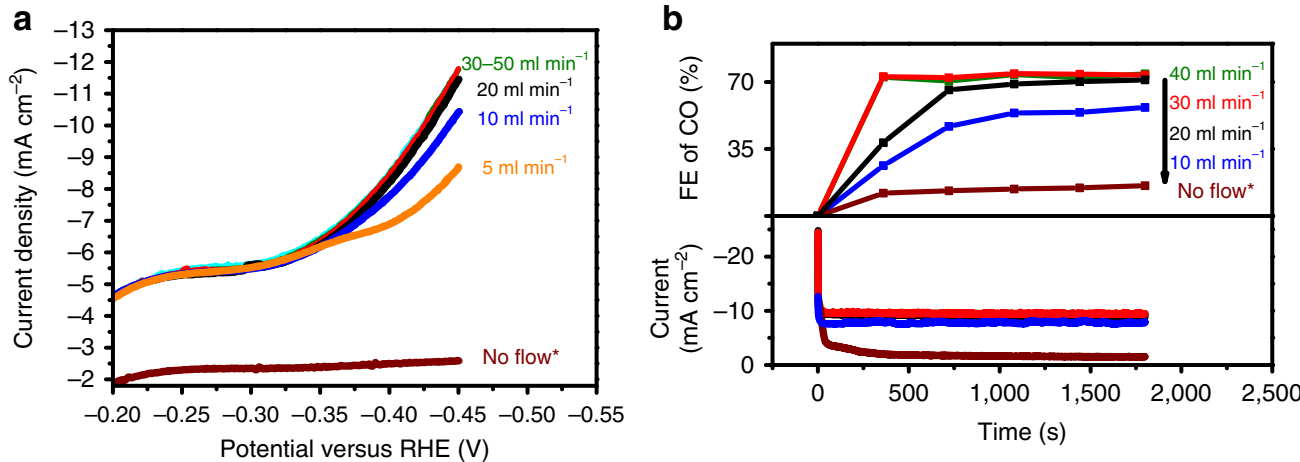

Figure 3 | Electrocatalytic performance as a function of gas flow rate. (a) Linear polarization curves obtained at different gas flow rates of $\mathrm{CO}_{2}$ (scan rate $50 \mathrm{mVs}^{-1}$ ). (b) FE towards $\mathrm{CO}$ for different flow rates of $\mathrm{CO}_{2}$ and the corresponding current densities (applied potential was -0.4 versus RHE and electrolyte concentration $0.3 \mathrm{M} \mathrm{KHCO}_{3}$ ). ${ }^{\star}$ The experiment was performed in $\mathrm{CO}_{2}$ saturated solutions. 


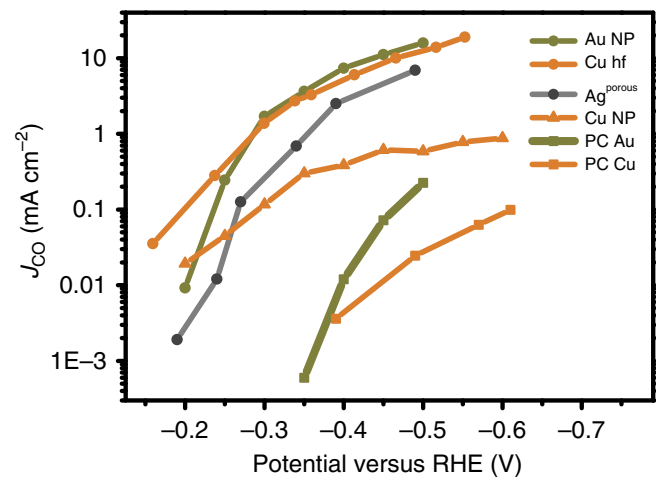

Figure 4 | Activity of various electrodes in water. Comparison of the performance of different electrodes on the basis of the partial current density with CO at variable potentials. Data are derived from refs 9,11,20.

hollow fibre to air before introduction in the vacuum chamber of the XPS apparatus (Supplementary Figs 8 and 9). More importantly, the similarity in binding energy of the $\mathrm{Cu} 2 p$ peaks before and after preparation or electrolysis suggests alloy or carbide formation on annealing or electrolysis is very unlikely, and that the activity is indeed associated with specific copper sites.

In addition to the activity comparison given in Fig. 4, comparison of the performance of hollow fibres and GDEs is useful, as the latter are typically used to induce electrochemical processes at gas-liquid-solid interfaces efficiently. Unfortunately, in most of the studies evaluating Cu-based GDE performance in $\mathrm{CO}_{2}$ reduction, high overpotentials $(>1 \mathrm{~V})$ have been applied, which are needed to stimulate hydrocarbon formation ${ }^{44,45}$. Although very high current densities $\left(0.1 \mathrm{~A} \mathrm{~cm}^{-2}\right.$ up to $1 \mathrm{~A} \mathrm{~cm}^{-2}$ ) have been reported at these potentials 8,46 , CO formation is usually not feasible, as evident from data reported for Ag-GDEs requiring an onset potential of around $-0.6 \mathrm{~V}$ versus RHE, to initiate performance ${ }^{47}$. The thickness of the porous catalyst layer used in GDEs is typically in the range from 5 to $20 \mu \mathrm{m}$ (ref. 48), similar to that of $15-20 \mu \mathrm{m}$ determined for our $\mathrm{Cu}$ hollow fibres by electrodeposition of nickel and subsequent energy-dispersive X-ray analysis (see Supplementary Fig. 10 and Supplementary Methods for experimental details). This thickness is also comparable to the thickness of the oxide films used to prepare rough electrodes or electrodeposited 3D porous structures ${ }^{49}$. It should be noted that the geometrical current density of the fibres has been calculated by normalizing the current to the outer surface area of the cylindrical morphology, in agreement with the convention for reporting current densities of GDEs ${ }^{8,50,51}$.

Although GDEs play an important role in fundamental electrocatalysis, mass production is limited by economic and technical issues ${ }^{48}$. On the contrary, a mature dry-wet spinning process allows mass production of organic hollow fibres, which are already commercially available ${ }^{52}$. Furthermore, preparation of metal hollow fibres with diameters in the range of $100-500 \mu \mathrm{m}$ was recently developed, implying great flexibility in the production of hollow fibres with variable diameters ${ }^{30,53}$. As a microtubular geometry has been applied in solid oxide fuel cells for some time, optimized stack design, sealing or current collection employed in this technology can be used to further optimize the configuration of metal hollow fibres when deployed for electrochemistry in liquid media 22,27 . Finally, we believe there is plenty of room to increase the electrochemical production rate by controlling the internal or external structure of the hollow fibres ${ }^{24,54,55}$. The thickness of the active catalyst layer can be tuned by changing the $3 \mathrm{D}$ geometry, the support material, the porosity and/or the precursor particle size.

In summary, the results reported in this article highlight a new electrode configuration to be explored for the development of robust electrolysis of $\mathrm{CO}_{2}$ at high rates in aqueous media. Employing a simple, compact $\mathrm{Cu}$ hollow fibre as both gas diffuser and cathode leads to very high $\mathrm{CO}$ production rates that are comparable to those achieved by use of noble metals. Selective formation of $\mathrm{CO}$ is observed with a maximum $\mathrm{FE}$ of $75 \%$ at a potential of $0.4 \mathrm{~V}$ versus RHE, when $\mathrm{CO}_{2}$ flow rates exceed $30 \mathrm{mlmin}^{-1}$. Partial current densities for $\mathrm{CO}_{2}$ reduction ranging from 2 to $17 \mathrm{~mA} \mathrm{~cm}^{-2}$ were obtained at moderate potentials $(-0.3$ to $-0.5 \mathrm{~V}$ versus RHE). The remarkable electrocatalytic performance of the electrodes is attributed to a defect-rich porous structure in addition to extraordinary favourable mass transport conditions. Hollow fibre-based electrodes might generally be a promising solution to stimulate electrochemical reactions in which at least one gas-phase reactant with low solubility is involved.

\section{Methods}

Preparation of copper hollow fibres. Commercially available copper powder (Skyspring nanomaterials, 99\%) with a particle size of $1-2 \mu \mathrm{m}$ was used as catalyst precursor (see Supplementary Table 3 and Supplementary Fig. 9). N-methylpyrrolidone (NMP, $99.5 \mathrm{wt} \%$, Sigma Aldrich) and Polyetherimide (PEI, Ultem 1,000, General Electric) were used as solvent and polymer, respectively. Copper powder (71.09 wt\%) was added to NMP (22.14 wt\%) followed by stirring and ultrasonic treatment for $30 \mathrm{~min}$. After addition of PEI $(6.76 \mathrm{wt} \%)$, this mixture was heated and kept at $50{ }^{\circ} \mathrm{C}$ and $60^{\circ} \mathrm{C}$ for $30 \mathrm{~min}$ and $2 \mathrm{~h}$, respectively. Next, the solution was allowed to cool down by stirring overnight, followed by degassing. Vacuum was applied for $90 \mathrm{~min}$ and the mixture was subsequently left overnight.

Spinning was carried out at room temperature $\left(21 \pm 3^{\circ} \mathrm{C}\right)$ using a stainless steel vessel, which was pressurized at 1 bar using nitrogen. The mixture was pressed through a spinneret (inner and outer diameters of 0.8 and $2.0 \mathrm{~mm}$, respectively) into a coagulation bath containing tap water. Deionized water was pumped through the bore of the spinneret with a speed of $30 \mathrm{ml} \mathrm{min}^{-1}$ and the so-called air gap was set to $1 \mathrm{~cm}$.

After spinning, the fibres were kept in a coagulation bath for 1 day to remove traces of NMP, followed by drying for 1 day. The green $\mathrm{Cu}$ hollow fibres were thermally treated at $600{ }^{\circ} \mathrm{C}$ for $3 \mathrm{~h}$ (heating rate and cooling rates: $60^{\circ} \mathrm{Ch}^{-1}$ ) in air to remove the PEI and induce sintering of the copper particles. The oxidized hollow fibres were reduced by hydrogenation at $280^{\circ} \mathrm{C}$ for $1 \mathrm{~h}$ in gas flow of $4 \% \mathrm{H}_{2}$ in balance gas Argon. Heating rates and cooling rates applied were $100{ }^{\circ} \mathrm{Ch}^{-1}$. X-ray diffraction patterns were collected using a Bruker D2 Phaser X-ray diffractometer, equipped with a $\mathrm{Cu}-\mathrm{K} \alpha$ radiation source and operated at $30 \mathrm{kV}$ and $10 \mathrm{~mA}$. SEM images were taken using a Phillips FEI XL30 FEG-ESEM or FEI Sirion HR-SEM. The locations of the taken images are shown in Supplementary Fig. 10. XPS were recorded using a Quantera SXM (Scanning XPS microprobe) spectrometer equipped with an $\mathrm{Al} \mathrm{K} \alpha(1,486.6 \mathrm{eV}) \mathrm{X}$-ray source. The source was operated at a $25-\mathrm{W}$ emission power, beam size of $200 \mu \mathrm{m}$ and pass energy of $224 \mathrm{eV}$. The resolution of the spectrometer was equivalent to 0.1 or $0.2 \mathrm{eV}$ for high-resolution scans of elements or the overall survey spectra of the Cu fibres, respectively. Further details of the method used to quantify (relative) elemental composition can be found in the Supplementary Methods description.

Electrochemical $\mathbf{C O}_{2}$ reduction. All solutions were prepared and all glasswares were cleaned by using deionized water (Millipore MilliQ, 18.2 M $\Omega$ ).

Electrochemical $\mathrm{CO}_{2}$ reduction activity of $\mathrm{Cu}$ hollow fibres was measured by using a three-electrode assembly in a glass cell at room temperature and pressure. A Princeton Applied Research VersaSTAT 3 potentiostat was used to control the potential. The cell compartment of the counter electrode, made of Pt mesh, was separated from the working electrode by using a Nafion 112 membrane (Sigma Aldrich). A Ag/AgCl ( $3 \mathrm{M} \mathrm{NaCl}, \mathrm{BASI})$ reference electrode was placed near the working electrode by using a Luggin capillary and all the potentials were converted to the RHE scale using the well-known Nernst relation. Voltage drop was measured before the electrolysis and after the experiments manually compensated for. $\mathrm{Cu}$ hollow fibres $(4 \pm 0.5 \mathrm{~cm}$ long) were used as working electrode and gas diffuser. The fibres were sealed at the bottom by using epoxy glue and connected to the gas inlet of the cell. The cathodic compartment was filled with $100 \mathrm{ml}, 0.3 \mathrm{M} \mathrm{KHCO}_{3}$ (99.95\%, Sigma Aldrich) solution and purged with $\mathrm{CO}_{2}$ for at least $20 \mathrm{~min}$ before the start of the experiments. During the electrolysis, $\mathrm{CO}_{2}$ was purged continuously through the fibre at a rate of $20 \mathrm{ml} \mathrm{min}^{-1}$, unless otherwise indicated. The composition of the gas was sampled via gas chromatography every $6 \mathrm{~min}$. $\mathrm{CO}, \mathrm{CO}_{2}$, $\mathrm{H}_{2}$ and hydrocarbons were separated using two different columns (a ShinCarbon $2 \mathrm{~m}$ micropacked column and a Rtx-1 column). A thermal conductivity detector 
and flame ionization detector were used to perform the quantitative analysis of the gas-phase products. The time needed to reach steady-state concentration was $\sim 10 \mathrm{~min}$; thus, the reaction was performed for at least $20 \mathrm{~min}$ at each experimental condition. A control experiment was conducted at $-0.5 \mathrm{~V}$ versus RHE under argon atmosphere. $\mathrm{CO}$ was not detected in such experiment, showing that residues of the polymers used during preparation of the hollow fibres did not contribute to $\mathrm{CO}$ formation in the electrochemical $\mathrm{CO}_{2}$ reduction experiments. Liquid products formed during electrolysis were analysed by using HPLC. A Prominence HPLC set up of Shimadzu was used, equipped with an Aminex HPX 87-H column from Biorad $^{4}$.

\section{References}

1. Buitenwerf, R., Rose, L. \& Higgins, S. I. Three decades of multi-dimensional change in global leaf phenology. Nat. Clim. Change 5, 364-368 (2015).

2. Hughes, L. Biological consequences of global warming: is the signal already apparent? Trends Ecol. Evol. 15, 56-61 (2000).

3. Root, T. L. et al. Fingerprints of global warming on wild animals and plants. Nature 421, 57-60 (2003).

4. Aresta, M. in Carbon Dioxide as Chemical Feedstock (ed. Aresta, M.) (Wiley-VCH, 2010).

5. Blankenship, R. E. et al. Comparing photosynthetic and photovoltaic efficiencies and recognizing the potential for improvement. Science 332, 805-809 (2011).

6. Zhan, Z. et al. Syngas production by coelectrolysis of $\mathrm{CO}_{2} / \mathrm{H}_{2} \mathrm{O}$ : the basis for a renewable energy cycle. Energy Fuels 23, 3089-3096 (2009).

7. Kondratenko, E. V., Mul, G., Baltrusaitis, J., Larrazábal, G. O. \& Pérez-Ramírez, J. Status and perspectives of $\mathrm{CO}_{2}$ conversion into fuels and chemicals by catalytic, photocatalytic and electrocatalytic processes. Energ. Environ. Sci. 6, 3112-3135 (2013).

8. Whipple, D. T. \& Kenis, P. J. Prospects of $\mathrm{CO}_{2}$ utilization via direct heterogeneous electrochemical reduction. J. Phys. Chem. Lett. 1, 3451-3458 (2010).

9. Lu, Q. et al. A selective and efficient electrocatalyst for carbon dioxide reduction. Nat. Commun. 5, 3242 (2014).

10. Zhu, W. et al. Active and selective conversion of $\mathrm{CO}_{2}$ to $\mathrm{CO}$ on ultrathin $\mathrm{Au}$ nanowires. J. Am. Chem. Soc. 136, 16132-16135 (2014).

11. Chen, Y., Li, C. W. \& Kanan, M. W. Aqueous $\mathrm{CO}_{2}$ reduction at very low overpotential on oxide-derived Au nanoparticles. J. Am. Chem. Soc. 134, 19969-19972 (2012)

12. Medina-Ramos, J., DiMeglio, J. L. \& Rosenthal, J. Efficient reduction of $\mathrm{CO}_{2}$ to $\mathrm{CO}$ with high current density using in situ or ex situ prepared Bi-based materials. J. Am. Chem. Soc. 136, 8361-8367 (2014).

13. Rosen, B. A. et al. Ionic liquid-mediated selective conversion of $\mathrm{CO}_{2}$ to $\mathrm{CO}$ at low overpotentials. Science 334, 643-644 (2011).

14. Jones, J. P., Prakash, G. \& Olah, G. A. Electrochemical $\mathrm{CO}_{2}$ reduction: recent advances and current trends. Isr. J. Chem. 54, 1451-1466 (2014).

15. Roberts, F. S., Kuhl, K. P. \& Nilsson, A. High selectivity for ethylene from carbon dioxide reduction over copper nanocube electrocatalysts. Angew. Chem. Int. Ed. 127, 5268-5271 (2015).

16. Kas, R. et al. Electrochemical $\mathrm{CO}_{2}$ reduction on $\mathrm{Cu}_{2} \mathrm{O}$-derived copper nanoparticles: controlling the catalytic selectivity of hydrocarbons. Phys. Chem. Chem. Phys. 16, 12194-12201 (2014).

17. Gattrell, M., Gupta, N. \& Co, A. A review of the aqueous electrochemical reduction of $\mathrm{CO}_{2}$ to hydrocarbons at copperJ. Electroanal. Chem. 594, 1-19 (2006).

18. Kuhl, K. P., Cave, E. R., Abram, D. N. \& Jaramillo, T. F. New insights into the electrochemical reduction of carbon dioxide on metallic copper surfaces. Energ. Environ. Sci. 5, 7050-7059 (2012).

19. Hori, Y. in Modern Aspects of Electrochemistry Vol. 42 (eds Vayenas, C. G., White, R. E. \& Gambao-Aldaco, M. E.) 89-189 (Springer, 2008).

20. $\mathrm{Li}, \mathrm{C} . \mathrm{W}$. \& Kanan, M. W. $\mathrm{CO}_{2}$ reduction at low overpotential on $\mathrm{Cu}$ electrodes resulting from the reduction of thick $\mathrm{Cu}_{2} \mathrm{O}$ films. J. Am. Chem. Soc. 134, 7231-7234 (2012).

21. Schouten, K., Kwon, Y., Van der Ham, C., Qin, Z. \& Koper, M. A new mechanism for the selectivity to $C_{1}$ and $C_{2}$ species in the electrochemical reduction of carbon dioxide on copper electrodes. Chem. Sci. 2, 1902-1909 (2011).

22. Othman, M. H. D., Droushiotis, N., Wu, Z., Kelsall, G. \& Li, K. Highperformance, anode-supported, microtubular SOFC prepared from single-stepfabricated, dual-layer hollow fibers. Adv. Mater. 23, 2480-2483 (2011).

23. Droushiotis, N., Doraswami, U., Kelsall, G. \& Li, K. Micro-tubular solid oxide fuel cells fabricated from hollow fibres. J. Appl. Electrochem. 41, 1005-1012 (2011).

24. Han, D. et al. Optimizing oxygen transport through $\mathrm{La}_{0.6} \mathrm{Sr}_{0.4} \mathrm{Co}_{0.2} \mathrm{Fe}_{0.8} \mathrm{O}_{3-\delta}$ hollow fiber by microstructure modification and $\mathrm{Ag} / \mathrm{Pt}$ catalyst deposition. Energy Fuels 26, 4728-4734 (2012).

25. Zuo, K. et al. Carbon filtration cathode in microbial fuel cell to enhance wastewater treatment. Bioresour. Technol. 185, 426-430 (2015).
26. Katuri, K. P. et al. A novel anaerobic electrochemical membrane bioreactor (AnEMBR) with conductive hollow-fiber membrane for treatment of low-organic strength solutions. Energ. Environ. Sci. 48, 12833-12841 (2014).

27. Gendel, Y., Roth, H., Rommerskirchen, A., David, O. \& Wessling, M. A microtubular all CNT gas diffusion electrode. Electrochem. Commun. 46, 44-47 (2014).

28. Meng, B., Tan, X., Meng, X., Qiao, S. \& Liu, S. Porous and dense Ni hollow fibre membranes. J. Alloys Compd. 470, 461-464 (2009).

29. Luiten-Olieman, M. W. et al. Porous stainless steel hollow fibers with shrinkage-controlled small radial dimensions. Scr. Mater. 65, 25-28 (2011).

30. Luiten-Olieman, M. W. et al. Towards a generic method for inorganic porous hollow fibers preparation with shrinkage-controlled small radial dimensions, applied to $\mathrm{Al}_{2} \mathrm{O}_{3}, \mathrm{Ni}, \mathrm{SiC}$, stainless steel, and YSZ. J. Membr. Sci. 407, 155-163 (2012).

31. Tang, W. et al. The importance of surface morphology in controlling the selectivity of polycrystalline copper for $\mathrm{CO}_{2}$ electroreduction. Phys. Chem. Chem. Phys. 14, 76-81 (2012).

32. Hori, Y., Murata, A. \& Takahashi, R. Formation of hydrocarbons in the electrochemical reduction of carbon dioxide at a copper electrode in aqueous solution. J. Chem. Soc. Faraday Trans. 1 85, 2309-2326 (1989).

33. Zhang, Y.-J., Sethuraman, V., Michalsky, R. \& Peterson, A. A. Competition between $\mathrm{CO}_{2}$ reduction and $\mathrm{H} 2$ evolution on transition-metal electrocatalysts. ACS Catal. 4, 3742-3748 (2014).

34. Schouten, K. J. P., Qin, Z., Gallent, E. P. R. \& Koper, M. T. Two pathways for the formation of ethylene in $\mathrm{CO}$ reduction on single-crystal copper electrodes. J. Am. Chem. Soc. 134, 9864-9867 (2012).

35. Durand, W. J., Peterson, A. A., Studt, F., Abild-Pedersen, F. \& Nørskov, J. K. Structure effects on the energetics of the electrochemical reduction of $\mathrm{CO}_{2}$ by copper surfaces. Surf. Sci. 605, 1354-1359 (2011).

36. Kas, R., Kortlever, R., Yılmaz, H., Koper, M. \& Mul, G. Manipulating the hydrocarbon selectivity of copper nanoparticles in $\mathrm{CO}_{2}$ electroreduction by process conditions. ChemElectroChem. 2, 354-358 (2015).

37. Gennaro, A. et al. Mechanism of the electrochemical reduction of carbon dioxide at inert electrodes in media of low proton availability. J. Chem. Soc. Faraday Trans. 92, 3963-3968 (1996).

38. Hori, Y. et al. "Deactivation of copper electrode" in electrochemical reduction of $\mathrm{CO}_{2}$. Electrochim. Acta 50, 5354-5369 (2005).

39. Sen, S., Liu, D. \& Palmore, G. T. R. Electrochemical reduction of $\mathrm{CO}_{2}$ at copper nanofoams. ACS Catal. 4, 3091-3095 (2014).

40. Vassiliev, Y. B., Bagotsky, V., Osetrova, N., Khazova, O. \& Mayorova, N. Electroreduction of carbon dioxide: Part I. The mechanism and kinetics of electroreduction of $\mathrm{CO}_{2}$ in aqueous solutions on metals with high and moderate hydrogen overvoltages. J. Electroanal. Chem. Interfacial. Electrochem. 189, 271-294 (1985).

41. Ma, M., Djanashvili, K. \& Smith, W. A. Selective electrochemical reduction of $\mathrm{CO}_{2}$ to $\mathrm{CO}$ on $\mathrm{CuO}$-derived $\mathrm{Cu}$ nanowires. Phys. Chem. Chem. Phys. 17, 20861-20867 (2015).

42. Verdaguer-Casadevall, A. et al. Probing the active surface sites for CO reduction on oxide-derived copper electrocatalysts. J. Am. Chem. Soc. 137, 9808-9811 (2015).

43. Reske, R., Mistry, H., Behafarid, F., Roldan Cuenya, B. \& Strasser, P. Particle size effects in the catalytic electroreduction of $\mathrm{CO}_{2}$ on $\mathrm{Cu}$ nanoparticles. J. Am Chem. Soc. 136, 6978-6986 (2014).

44. Yano, H., Tanaka, T., Nakayama, M. \& Ogura, K. Selective electrochemical reduction of $\mathrm{CO}_{2}$ to ethylene at a three-phase interface on copper (I) halide-confined $\mathrm{Cu}$-mesh electrodes in acidic solutions of potassium halides. J. Electroanal. Chem. 565, 287-293 (2004).

45. Cook, R. L., MacDuff, R. C. \& Sammells, A. F. High rate gas phase $\mathrm{CO}_{2}$ reduction to ethylene and methane using gas diffusion electrodes. $J$. Electrochem. Soc. 137, 607-608 (1990).

46. Peterson, A. A., Abild-Pedersen, F., Studt, F., Rossmeisl, J. \& Nørskov, J. K. How copper catalyzes the electroreduction of carbon dioxide into hydrocarbon fuels. Energ. Environ. Sci. 3, 1311-1315 (2010).

47. Thorson, M. R., Siil, K. I. \& Kenis, P. J. Effect of cations on the electrochemical conversion of $\mathrm{CO}_{2}$ to CO. J. Electrochem. Soc. 160, F69-F74 (2013).

48. Suddhasatwa, B. Recent Trends in Fuel Cell Science and Technology (Springer, 2007).

49. Lu, Q., Rosen, J. \& Jiao, F. Nanostructured metallic electrocatalysts for carbon dioxide reduction. ChemCatChem. 7, 38-47 (2015).

50. Furuya, N., Yamazaki, T. \& Shibata, M. High performance Ru-Pd catalysts for $\mathrm{CO}_{2}$ reduction at gas-diffusion electrodes. J. Electroanal. Chem. 431, 39-41 (1997).

51. Kim, B., Ma, S., Molly Jhong, H.-R. \& Kenis, P. J. A. Influence of dilute feed and $\mathrm{pH}$ on electrochemical reduction of $\mathrm{CO}_{2}$ to $\mathrm{CO}$ on $\mathrm{Ag}$ in a continuous flow electrolyzer. Electrochim. Acta 166, 271-276 (2015).

52. Baker, R. W. Membrane Technology and Applications (McGrawHill, 2000). 
53. David, O., Gendel, Y. \& Wessling, M. Tubular macro-porous titanium membranes. J. Membr. Sci. 461, 139-145 (2014).

54. Luiten-Olieman, M. W., Winnubst, L., Nijmeijer, A., Wessling, M. \& Benes, N. E. Porous stainless steel hollow fiber membranes via dry-wet spinning. J. Membr. Sci. 370, 124-130 (2011).

55. de Wit, P. et al. Highly permeable and mechanically robust silicon carbide hollow fiber membranes. J. Membr. Sci. 475, 480-487 (2015).

\section{Acknowledgements}

This work is supported by NanoNextNL, a micro and nanotechnology consortium of the Government of the Netherlands and 130 partners.

\section{Author contributions}

R.Ka. designed and performed electrochemistry experiments and surface characterization, and wrote the manuscript. K.K.H. performed additional electrochemical experiments, prepared several hollow fibres and assisted R.Ka. in the analysis of the data. R.Ko. performed the HPLC experiments and contributed to the interpretation of the electrochemical data. A.M. performed the electron microcopy studies and analysed these data. P.d.W. and M.W.J.L. prepared Cu hollow fibres and interpreted the physical characterization of these. M.T.M.K. provided the use of facilities and advised on the interpretation of the electrochemical data. N.E.B. supervised the design and interpretation of the analysis of the hollow fibres. G.M. interpreted all the data and co-wrote the manuscript. G.M. and N.E.B. together conceived the idea. All authors contributed to improvement of the wording of the manuscript.

\section{Additional information}

Supplementary Information accompanies this paper at http://www.nature.com/ naturecommunications

Competing financial interests: The authors declare no competing financial interests.

Reprints and permission information is available online at http://npg.nature.com/ reprintsandpermissions/

How to cite this article: Kas, R. et al. Three-dimensional porous hollow fibre copper electrodes for efficient and high-rate electrochemical carbon dioxide reduction. Nat. Commun. 7:10748 doi: 10.1038/ncomms10748 (2016).

\section{(c) (1)}

This work is licensed under a Creative Commons Attribution 4.0 International License. The images or other third party material in this article are included in the article's Creative Commons license, unless indicated otherwise in the credit line; if the material is not included under the Creative Commons license, users will need to obtain permission from the license holder to reproduce the material. To view a copy of this license, visit http://creativecommons.org/licenses/by/4.0/ 